\title{
Mobile phone dependence and its relation with mood states
}

\author{
among adolescents
}

\author{
Nupur Chauhan $^{1 *}$, Dr. Madhu Jain ${ }^{2}$
}

\section{ABSTRACT}

The present study was planned to investigate the relationship between the mobile phone dependence and mood states among adolescents. The sample of the present study consisted of 100 school going adolescents 50 boys and 50 girls. Test of Mobile Phone Dependence developed by Choliz (2010) and Eight State Questionnaire by Curran and Cattell (1989) were used to assess the level of mobile phone dependence and the mood states among adolescents. Results showed that the excessive dependence on mobile phones is significantly correlated with mood states among adolescents, however, no signs of serious level of depression is found in both boys and girls due to mobile phones. It was also observed that adolescents primarily use their phones to access social networking platforms than for other purposes. The excessive use of mobile dependence pattern is related to higher negative psychosocial costs. Hence, there is an urgent requirement to take notice about the amplified use of mobile phones by the adolescents and generate awareness about the ill effects in society.

Keywords: mobile phone dependence, mood states, adolescents

$\mathbf{M}$ ankind has made tremendous technological advancement over thousands of years, from "Stone Age" technology to this day information technology. With the arrival of newer technologies, the life of human beings has become progressively easier. Mobile technology has experienced an incredible growth. In 1946, Swedish mobile used the first primary official mobile. In 1983, Motorola presented 1st truly portable telephone. Mobile is among the foremost prominent sorts of information and technology (ICT) and is perhaps also the one that has shown the foremost spectacular development during the past few years with reference to technological innovations, social impact, and general use by the bulk of the population. Consistent with the recent statistics, India has the 2nd largest mobile customer base, after China and it is estimated that the customer base is expanding in India at a faster pace than that of China.

Each and every invention comes up with comforts along with some threatening effects. Same is the case with mobile phone technology. While mobile phones are extremely attractive as a tool for communication and interpersonal interaction, there has been an

\footnotetext{
${ }^{1}$ Research Scholar, University of Rajasthan, Jaipur, India

${ }^{2}$ Head of Department, University of Rajasthan, Jaipur, India

*Responding Author
}

Received: June 19, 2020; Revision Received: June 25, 2020; Accepted: September 25, 2020

(C) 2020, N Chauhan \& M Jain; licensee IJIP. This is an Open Access Research distributed under the terms of the Creative Commons Attribution License (www.creativecommons.org/licenses/by/2.0), which permits unrestricted use, distribution, and reproduction in any Medium, provided the original work is properly cited. 
increased risk in its problematic use. Psychiatrists proclaim that within the 21 st century, mobile addiction has become one among the main non-drug addictions. Alongside telephone dependence, there could also be psychiatric co morbidity (anxiety, ringxiety, depression, nomophobia, insomnia, headache, dizziness, decline in quality of life) or physical sequelae (hearing loss, eye strain, digital thumb, allergic dermatitis etc) or behavioural co- morbidity (internet addiction, sex addiction, pathological gambling, twiddling with different identities, projections and dissociation without consequences in real world, hyper personal communication within the sort of chats and online games etc.).

Palen et al. (2001) and Monk et al (2004) recognized the problematic dimension of excessive usage of mobile in children. Bianchi and Phillips (2005) also claimed that problematic use of the mobile has been associated with high neuroticism (i.e., the tendency to be emotionally unstable) and extraversion (i.e., the tendency to be sociable), whereas relationships with other personality traits (e.g., agreeableness, consciousness) were less consistent across studies. Ling (2005) identified a linkage between its usage and criminal activities like alcohol, fighting, theft and narcotics use. Niaz (2008) proposed that addictive mobile use has now become a key factor for public ill health and awareness about the risks related to excessive usage and addictive behaviours must be extended among folk. Billieux et al. (2008) emphasized that impulsivity strongly predicts problematic mobile use. Leung (2008) claimed that low self-esteem was demonstrated as a robust predictor of dysfunctional use. These results were generally interpreted within the sense that individuals with low selfesteem often experience the necessity to hunt reassurance by contacting people, which makes them vulnerable to excessive use and dependence on the mobile.

Morrill (2009) studied the changes in adolescent development since mobile phones became an integral aspect in American society and explained the impacts on adolescent's psychosocial development. Lee (2012) argued that the factor that affects smart phone addiction is habitual overuse, thanks to smart phone's convenience and playfulness, which results in later life problems. Jung and Ha (2013) has studied about the consequences of stress and emotional expression that affect smart phone addiction among grade school students and located out that the higher the strain associated with studying and therefore the negative emotional expression was, the higher the smart phone addiction rate was. Jeong et al. (2015) examined the user characteristics and media content types which causes mobile addiction. With reference to the user characteristics, results showed that those that have lower self-control and people who have greater stress were more likely to be hooked in to smart phones. For media content types, those that use smartphones for social networking sites, games and entertainment were more likely to be hooked in to smartphones, whereas those that use it for study related purposes weren't .

Mood is a generalized internal state of feeling. Moods generally have either a positive or negative valence. Researchers have conducted many studies on the sources of moods and have identified important sources like personality, day of the week, time of the day, stress, social activities, sleep, age and gender. More recently a spread of mobile services and applications have surfaced that are designed to assist users communicate information within the sort of short textual messages which frequently convey their mood. In a study conducted by Lu et al. (2009) in Japan, it had been found that depression was related to both internet dependency and text message dependency whereas anxiety was associated negatively with text message dependency. 


\section{METHODOLOGY}

\section{Sample}

The sample of the present study comprised of 100 school going adolescents, 50 boys and 50 girls of class IX with mean age 16.8 years. This sample is taken from two different schools of Jaipur, chosen on the basis of random sampling. The method of purposive sampling is used to select the adolescents for the study.

\section{Measures}

The following tools were used in the present study:

1. Test of Mobile Phone Dependence (TMP; Choliz, 2010): It is composed of three factors: abstinence, lack of control and problems, and tolerance. The final version consists of 22 items to assess these three factors of mobile phone dependence. It has high internal consistency (Cronbach alpha $=0.94)$. The corrected homogeneity index for each of the items was greater than 0.5: that is, the correlation between each of the items and the rest of the scale was equal to or greater than 0.5 , indicating that all the items measure the same construct, namely dependence on the mobile phone.

2. Eight State Questionnaire (8SQ; Curran and Cattell, 1973): 8SQ (form A) was designed specifically for measuring eight important states of mood, that is, anxiety, stress, depression, regression, fatigue, guilt, extraversion and arousal. It contains 96 items, 12 of which measure each state. This test was constructed to be used with adults and adolescents of 16 years of age and above. The reliability coefficients of the scale ranges from 0.26 to 0.48 and the concept validity of the scale ranges from 0.48 to 0.92 .

\section{Procedure}

The sample was selected from the Jaipur city. After deciding the tools to be used for the research purpose, the investigation was carried out. Inclusion and exclusion criteria for selection of the subjects were strictly followed. Each scale was administered separately and independently with adequate intervals keeping the motivational and attention factors of the adolescents in view.

\section{Statistical Analysis}

Keeping in view the objectives as well as the design of the study, Pearson's coefficient of correlation was used for the analysis of data. Separate correlational analysis was done for boys and girls.

\section{RESULTS}

Table 1: Mean scores on test of mobile phone dependence for boys $(N=50)$

\begin{tabular}{|l|l|}
\hline Subscales & Mean \\
\hline Abstinence & 30.14 \\
\hline Lack of control and problems & 18.95 \\
\hline Tolerance and interference & 21.76 \\
\hline
\end{tabular}

Table 2: Mean scores on test of mobile phone dependence for girls $(N=50)$

\begin{tabular}{|l|l|}
\hline Subscales & Mean \\
\hline Abstinence & 27.42 \\
\hline Lack of control and problems & 12.19 \\
\hline Tolerance and interference & 17.68 \\
\hline
\end{tabular}


As evidenced in Table 1, 50 boys participated in the study, their mean scores for the first factor, that is, abstinence is 30.14. Likewise, in the second factor of lack of control and problems, the mean score is 18.95 . In the last factor of tolerance and interference, boys have a mean score of 21.76

Like boys, equal number of girls was selected for this study, that is, 50. In the first factor, that is, abstinence, the mean score of girls was found to be 27.42. The mean score of girls for second factor, that is, lack of control and problems is 12.19. In the last factor of tolerance and interference mean score is 17.68. Table 2

Table 3: Coefficient of correlation (r) between mobile phone dependence and mood states among boys $(N=50)$

\begin{tabular}{|l|l|l|l|}
\hline $\begin{array}{l}\text { Mobile phone } \\
\text { dependence }\end{array}$ & Abstinence & $\begin{array}{l}\text { Lack of control and } \\
\text { problems }\end{array}$ & $\begin{array}{l}\text { Tolerance and } \\
\text { interference }\end{array}$ \\
\cline { 1 - 3 } Mood States & & & \\
\hline Anxiety & $0.45^{* *}$ & -0.04 & $0.65^{* *}$ \\
\hline Stress & $0.32^{*}$ & $0.43 * *$ & $0.28^{*}$ \\
\hline Depression & 0.10 & 0.15 & -0.13 \\
\hline Regression & $0.47^{* *}$ & $0.38 * *$ & 0.18 \\
\hline Fatigue & -0.12 & 0.09 & -0.03 \\
\hline Guilt & $0.33^{*}$ & 0.20 & 0.22 \\
\hline Extraversion & $-0.44^{* *}$ & -0.14 & $0.42 * *$ \\
\hline Arousal & $0.29 *$ & -0.13 & $0.58^{* *}$ \\
\hline$* \mathrm{P}<0.05$ & $* * \mathrm{P}<0.01$ & & \\
\hline
\end{tabular}

The overview of Table 4 reveals that the first factor of mobile phone dependence, that is, abstinence, which refers to the discomfort felt when unable to use mobile phone and to the use of these phones to alleviate psychological problems, is significantly correlated to anxiety $(\mathrm{r}=0.45, \mathrm{p}<0.01)$, stress $(\mathrm{r}=0.32, \mathrm{p}<0.05)$, regression $(\mathrm{r}=0.47, \mathrm{p}<0.01)$, guilt $(\mathrm{r}=0.33, \mathrm{p}<0.05)$, arousal $(\mathrm{r}=0.29, \mathrm{p}<0.05)$ and negatively correlated to extraversion $(\mathrm{r}=-0.44, \mathrm{p}<0.05)$ among boys. The second factor of mobile phone dependence, that is, lack of control and problems which denotes to the difficulty of stopping mobile phone use despite efforts to do so, has obtained significantly correlated to only two dimensions of mood states for boys, stress $(\mathrm{r}=0.43, \mathrm{p}<0.01)$ and regression $(\mathrm{r}=0.38, \mathrm{p}<0.01)$. The last factor, called tolerance and interference is significantly correlated to the following four mood states - anxiety ( $\mathrm{r}=0.65$, $\mathrm{p}<0.01)$, stress $(\mathrm{r}=0.28, \mathrm{p}<0.01)$, extraversion $(\mathrm{r}=0.42, \mathrm{p}<0.01)$ and lastly arousal $(\mathrm{r}=0.58$, $\mathrm{p}<0.01)$. It can be seen that the mood states of fatigue and depression is not correlated to any of the factors of mobile phone dependence among boys.

Table 4 : Coefficient of correlation (r) between mobile phone dependence and mood states among girls $(N=50)$

\begin{tabular}{|c|c|c|c|}
\hline $\begin{array}{l}\text { Mobile phone } \\
\text { dependence }\end{array}$ & \multirow[t]{2}{*}{ Abstinence } & \multirow[t]{2}{*}{$\begin{array}{l}\text { Lack of control and } \\
\text { problems }\end{array}$} & \multirow[t]{2}{*}{$\begin{array}{l}\text { Tolerance and } \\
\text { interference }\end{array}$} \\
\hline Mood States & & & \\
\hline Anxiety & $0.41 * *$ & -0.12 & $0.48 * *$ \\
\hline Stress & 0.19 & 0.21 & $0.32 *$ \\
\hline Depression & 0.05 & 0.09 & -0.17 \\
\hline Regression & $0.32 *$ & $0.35 *$ & $0.31 *$ \\
\hline Fatigue & -0.09 & 0.20 & -0.13 \\
\hline Guilt & $0.30 *$ & $0.47 * *$ & $0.34 *$ \\
\hline Extraversion & $-0.36^{*}$ & 0.08 & 0.18 \\
\hline Arousal & 0.21 & -0.07 & $0.32 *$ \\
\hline
\end{tabular}




\section{Mobile phone dependence and its relation with mood states among adolescents}

The results obtained above as shown in Table 5 reveals that the first factor of mobile phone dependence, called abstinence is significantly correlated to anxiety $(r=0.41 \mathrm{p}<0.01)$, regression $(r=0.32, p<0.05)$, guilt $(r=0.30, p<0.05)$ and negatively correlated to extraversion $(\mathrm{r}=-0.36, \mathrm{p}<0.05)$. The second factor called lack of control and problems, is found to be significantly correlated to only two dimensions of mood states, that is regression $(r=0.35$, $\mathrm{p}<0.05)$ and guilt $(\mathrm{r}=0.47, \mathrm{p}<0.01)$. The last factor, tolerance and interference with other activities the activity is significantly correlated to anxiety $(r=0.48, p<0.01)$, stress $(r=0.32$, $\mathrm{p}<0.05)$, regression $(\mathrm{r}=0.31, \mathrm{p}<0.05)$, guilt $(\mathrm{r}=0.34, \mathrm{p}<0.05)$ and arousal $(\mathrm{r}=0.32, \mathrm{p}<0.05)$ among girls.

\section{Fig. 1 Pattern of mobile use among adolescents}

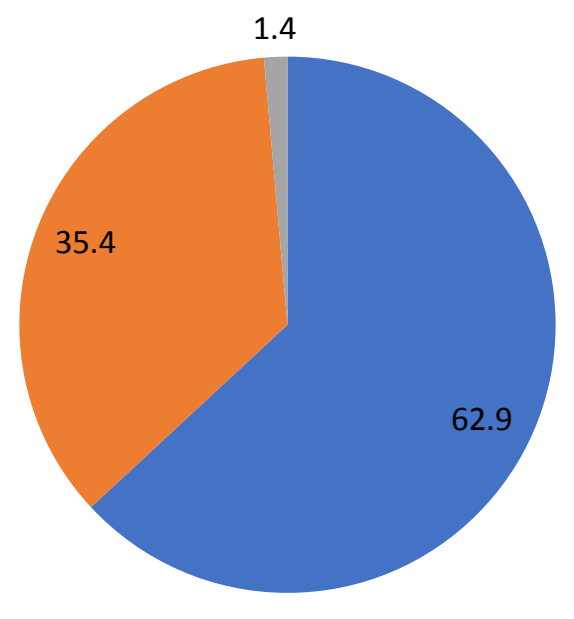

Online social networking

Calls

\section{DISCUSSION}

Mobile phones have emerged to become indispensable tools of lifestyle within the hands of mankind. The technology has gained its peak popularity within the period of last ten years. the arrival of various applications that provide the leisure of text messaging freed from cost, lower call rates and straightforward availability and accessibility of internet use on cellular phones are among the prominent causes resulting in the rise in its usage. Mobile phones have repercussions when projected to excessive use, which comes into the realm of variety of recognizable psychological illness.

In today's society, it's very rare to ascertain an adolescent without a mobile, while young children as young as seven years old have also been spotted with the device. Adolescents are prime users of mobile phones everywhere the planet. Nowadays it has become a standing symbol amongst them to possess a mobile with latest technology and latest applications. Adolescents are fascinated to the present technology at a really significant level. Verma (2014) concluded that extreme level of mobile usage also results in delusions, auditory and tactile hallucinations. Studies by Lin (2009), Oksman and Turtiainen (2012) explains that cellular phones provides a plethora of psychological benefits to the utilization, namely feelings of independence and autonomy with reference to owing the device and controlling its parameters, establishing and maintaining healthy relationships by means of voice call, text messaging or online social networking. It has been reported to be used as a standing symbol among peers, a continuing source of fun and games and also to extend inclusion and connectedness amongst family and friends. 


\section{Mobile phone dependence and its relation with mood states among adolescents}

On the basis of results, it has been seen that the dependence on the mobile is significantly associated with moods states among adolescents. Adolescents feel worried, tense, unorganized, easily annoyed and in poor spirits when unable to use mobile and consequently use mobile phone more frequently to alleviate the psychological problems. Ha et al. (2008) reported that adolescents feel anxiety due to inadequacy of access to mobile services sometimes, or because of feelings of social isolation and being neglected upon not receiving or sending text messages over a period time.

Adolescents feel difficult to stop the mobile phone use despite several efforts and hence it increases their tolerance level which makes them use the mobile more and more frequently. It results in drastic effects on their mood type and level. This corrobates with the study conducted at Baylor University (2013), consistent with which, those with a looking for endlessly checking their mobile phones were more susceptible to mood changes. Extroverts are more likely to be hooked and spend up to 10 hours each day on their phone. They also explained that an individual who is moody and temperamental could also be more likely to be hooked in to their phone.

However, no signs of serious level of depression are found in both boys and girls. this is could also be because the planet has become so technology friendly that massive number of alternatives are present to substitute the necessity for mobile phones. So when one cannot get access to the mobile, he or she may utilize the laptop, tablet, play station etc to unravel the specified purpose, whether it's going to be for getting connected with friends, for entertainment or for something else.

Lastly, when looked upon the pattern of usage of mobile phones, it gave the thought that these days approximately 50 percent of adolescents are using their mobile phones primarily for online social networking. These many include a good sort of websites and applications like Facebook, WhatsApp, Twitter, Telegram, BBM, Hike etc. These are mostly freed from costs and thus gives the chance to adolescents to remain connected with their friends that they already know and to form new friends from different parts of the planet.

It was also seen that they make use of their phones to make calls to their friends and family. Calls are seen as important source of interaction because it involves direct verbal communication between the people and has report and content delivery. Additionally, it was observed that the text messaging service was least used by the adolescents. This could be because of relatively high cost of messaging in comparison to social networking websites and thus sending messages to an outsized group of individuals would begin to be very costly, while an equivalent thing is often done at online social networking websites at free of cost.

Thus, in light of this findings it is suggested that various educational programs should be run in schools to extend awareness about the healthy usage of mobile and both, the adolescents and their parents, should be involved in these programmes. The excessive use of mobile dependence pattern is related to higher negative psychosocial consequences. Hence, there is an urgent need to take notice about the increased use of mobile phones by the adolescents and generate awareness about the ill effects in general public. Moreover, it is also advised that the some age regulation should be set for the adolescents, under which they will not be allowed to own their personal mobile. 
REFERENCES

Alavi, S. S., Ferdosi, M., Jannatifard, F., Eslami, M., Alaghemandan, H., \& Setare, M. (2012). Behavioral Addiction versus Substance Addiction: Correspondence of Psychiatric and Psychological Views. International journal of preventive medicine, 3(4), 290-294.

Bianchi, A., Phillips, J.G. (2005). Psychological predictors of problem mobile phone use. Cyber Psychology Behaviour, 8(1), 39-51. https://doi:10.1089/cpb.2005.8.39

Billieux, J., Van Der Linden, M., \& Rochat, L. (2008). The role of impulsivity in actual and problematic use of the mobile phone. Applied Cognitive Psychology, 22(9), 11951210. https://doi.org/10.1002/acp.1429

Chóliz, M. (2010). Mobile phone addiction in Adolescence. Evaluation and prevention of mobile addiction in teenagers. Saarbrücken: Lambert Academic Publishing.

Curran, J.P. \& Cattell, R.B. (1989). Eight State Questionnaire. New Delhi: The PsychoCentre.

Jeong, S.H., Kim, H.J. and Hwang, Y. (2016). What type of content are smartphone users addicted to? SNS vs. Games. Computers in Human Behaviour, 54. https://doi.org/10.1016/j.chb.2015.07.035

Jung, J.Y. \& Ha, J.H. (2013). The effects of general stress and emotional expression on upper grades of elementary school students' smart phone addiction. Journal of Family and Counselling 3: 61-77.

Kesari, K.K., Meena, R., Nirala, J., Kumar, J., Verma, H.N. (2014). Effect of 3G cell phone exposure with computer controlled 2-D stepper motor on non-thermal activation of the hsp27/p38MAPK stress pathway in rat brain. Cell Biochemistry Biophysics, 68(2),347-358. https://doi.org/10.1007/s12013-013-9715-4

Lee, K.Y. (2012). The study of factors in affecting the user's addictive behaviour in using the smart phone applications. Korean Journal of Business Education ,27, 183-208.

Leung, L. (2008). Linking psychological attributes to addiction and improper use of the mobile phone among adolescents in Hong Kong. Journal of Children and Media, 2, 93-113.

Ling, R. (2005). Mobile communications vis-à-vis teen emancipation, peer group integration and deviance. In the Inside Text: Social perspectives on SMS in the mobile age. London: Klewer.

Lu, X., Watanabe, J. \& Kitamura, T. (2011). Internet and mobile phone text messaging dependency: Factor structure and correlation with dysphoric mood among Japanese adults. Computers in Human Behaviour 27,1702-1709. https://doi.org/ 10.1016/j.chb.2011.02.009

Monk, A., Carroll, J, Parker, S. \& Blythe, M. (2007). Why are mobile phones annoying? Behaviour and Information Technology, 23, 33-41. https://doi.org/10.1080/01449290310001638496

Morrill, T.B. (2009). Cell phone use and psychosocial development among emerging adults [ PhD Dissertation, Utah State University, Logan, Utah]. ProQuest Dissertations and Theses. https://digitalcommons.usu.edu/cgi/viewcontent.cgi?article $=1744 \&$ context=etd

Niaz, U. (2008). Addiction with Internet and Mobile: An overview. Journal of Pakistan Psychiatric Society, 5(2), 72-75

Palen, L., Salzman, M. \& Youngs, E. (2001). Discovery and Integration of Mobile Communications in Everyday Life. Personal Ubiquitous Computer, 5, 109-122 (2001). https://doi.org/10.1007/s007790170014

Oksman, V. \& Turtiainen, J. (2004). Mobile Communication as a Social Stage. New Media \& Society, 6(3), 319-339. https://doi.org/10.1177/1461444804042518

(C) The International Journal of Indian Psychology, ISSN 2348-5396 (e)| ISSN: 2349-3429 (p) | 30 
Mobile phone dependence and its relation with mood states among adolescents

\section{Acknowledgements}

The author appreciates all those who participated in the study and helped to facilitate the research process.

\section{Conflict of Interest}

The author declared no conflict of interest.

How to cite this article: N Chauhan \& M Jain (2020). Mobile phone dependence and its relation with mood states among adolescents. International Journal of Indian Psychology, 8(3), 24-31. DIP:18.01.004/20200803, DOI:10.25215/0803.004 